\title{
The market for acquiring card payments from small and medium-sized Canadian merchants
}

\author{
Angelika Welte ${ }^{1} \cdot$ Jozsef Molnar $^{1}$
}

Published online: 1 April 2021

(c) National Association for Business Economics 2021

\begin{abstract}
This article builds on industry data and a unique dataset of small and medium-sized merchants to provide insights into the acquirer-merchant market in Canada. Three main findings are presented. First, smaller merchants pay their acquirer more for every dollar of card payment than larger merchants. Second, this finding is mainly explained by high fixed costs. Third, the acquiring market in Canada is concentrated and has remained fairly stable since 2010. These findings could be relevant for other countries with mature card payments systems such as the US and Australia.
\end{abstract}

Keywords Financial services $\cdot$ Market structure and pricing $\cdot$ Payment clearing and settlement systems

JEL Classifications $\mathrm{C} \cdot \mathrm{C} 2 \cdot \mathrm{D} \cdot \mathrm{D} 2 \cdot \mathrm{E} \cdot \mathrm{E} 4 \cdot \mathrm{E} 42$

\section{Introduction}

Globally, card payments and other electronic payment methods are displacing cash at the point of sale (POS). Countries with mature card payment systems still experience growth in card payments outpacing growth in personal consumption expenditure; examples include Canada, the United States, Australia, and a number of EU member states, as well as countries in the Asia-Pacific region. The Covid-19 pandemic has also highlighted the significance of non-POS or e-POS payments where non-cash payments are already dominant (Chen et al. 2020; Huynh et al. 2020). Given these changes, the economics of the card ecosystem has become a focus for researchers and business experts around the world.

The participants in the card ecosystem are the card networks, cardholders, issuers, merchants, and acquirers. In this article, we use industry data and merchant-level data from a survey of Canadian businesses to explore the relationship between acquirers and small and medium-sized merchants.

Acquirers are payment service providers who offer merchants access to the card networks; thus, they play a key role in card payments. To fix terminology, we use the term

Angelika Welte

awelte@bankofcanada.ca

1 Bank of Canada, Ottawa, Canada acquirer here for the company that facilitates this access. Some acquirers have direct access to the card network (fullservice acquirers), while others act as a third-party agent (TPA), or also processor (TPP), between the merchant and full-service acquirers. TPAs may provide merchant services as payment facilitators or independent sales organizations (ISO) for full-service acquirers or offer partial services to merchants who have an agreement with another acquirer. Although not directly connected, all major credit card networks such as Visa (2020) and MasterCard (2020) require TPAs to register with them.

In 2018, acquirers provided debit card services to almost 500,000 merchants and credit card services to about 1 million merchants in Canada. ${ }^{1}$ In the United States, the number of card-accepting merchants in 2018 was around 10.6 million (The Nilson Report).

Although the literature (Rochet and Tirole 2002) and industry experts (Van Duynhoven 2010) seems to imply that the Canadian acquiring market is efficient and even competitive, empirical work on fees merchants pay to acquirers and on market structure in Canada is lacking. A report by the

\footnotetext{
${ }^{1}$ See Interac (https://newsroom.interac.ca/interac-by-the-numbers/) and Canadian Bankers Association (https://cba.ca/credit-card-stati stics). Our data focus on small and medium-sized POS merchants, which explains why debit and credit card acceptance rates are both in the range of 60 to 70 percent. In contrast, the network data imply that credit cards are accepted by twice as many merchants as are debit cards.
} 
Fig. 1 Four-party card payment system. Notes Adapted from Tirole (2011). Amounts and fees are illustrative and reflect only transaction-level charges. MIF is the merchant interchange fee, NAF is the network access fee, $\mathrm{AM}$ is the acquirer margin, and MSC is the merchant service charge

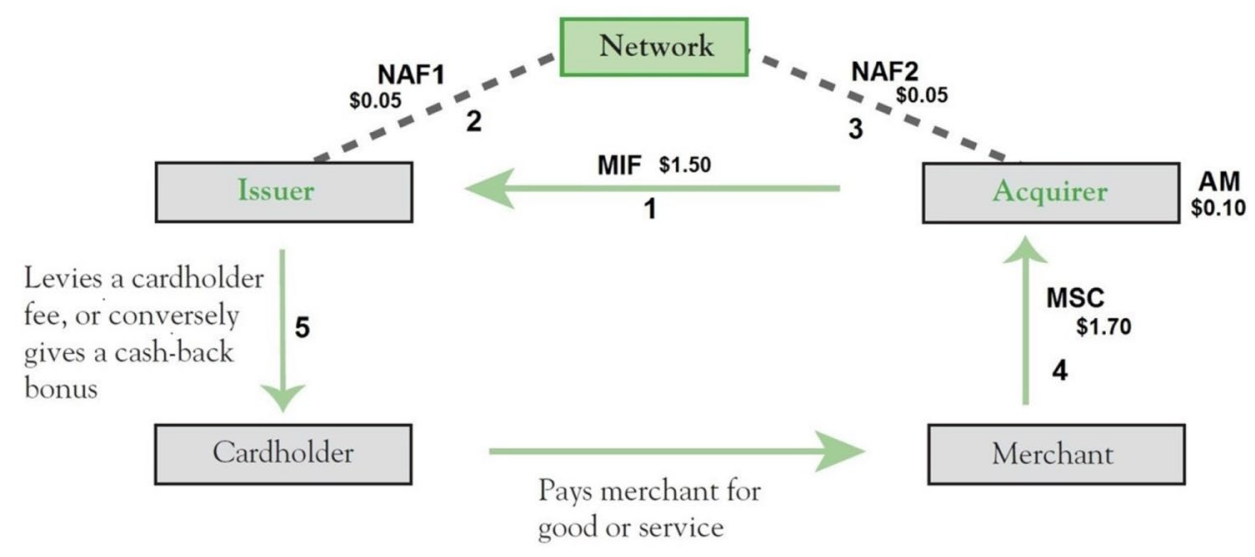

European Commission (2006) looks at the acquiring market in the EU-25 group of countries before the creation of the Single Euro Payments Area. Kjos (2007) discusses the US acquiring market, and Ho et al. (2020), using data on Chinese merchants, study a monopolistic acquiring market.

Kosse et al. (2017) compute the resource costs of providing cash and card payments in Canada. They use a representative sample of small and medium-sized businesses (SMBs) that responded to the 2015 Retailer Survey on the Cost of Payment Methods (RSCPM). They assume that acquirers' costs are equal to the fees they charge merchants. These fees blend fees remitted to other payment system participants with the acquirers' own fees, however. In subsequent work, Fung et al. (2018) find heterogeneity in merchant fees. These studies motivate us to analyze acquirer prices by size of business.

Three main findings contribute to our understanding of the Canadian acquiring market:

1. Based on the representative sample of SMBs in Kosse et al. (2017), we find that smaller merchants pay their acquirer more for every dollar of card payment than larger merchants.

2. Monthly fixed fees paid to the acquirer are proportionally more significant for merchants with lower card sales.

3. Four large acquirers process about 85 percent of card transactions in Canada. These four acquirers have direct access to networks. While we discuss potential drivers of the observed market structure, further research and empirical evidence, which are beyond the scope of this article, are needed to assess the efficiency of the Canadian acquiring market.

\section{The role of acquirers in a four-party card system}

Most card payments in Canada go through one of two major credit card networks, Visa and MasterCard, or the domestic debit card network, Interac. These card payment systems use a four-party model, where the acquiring, issuing, and network operations are separate (Fig. 1). ${ }^{2}$

Acquirers in the four-party system generally offer three types of service:

- signing up merchants for card networks and supplying them with the necessary equipment;

- authorizing, processing, and settling card payments and providing dispute resolution; and

- providing merchants with monthly statements and services, such as consulting or integration with accounting systems.

While some of these functions can also be taken on by TPAs, the acquirer with access to the network remains liable for compliance with network rules and final dispute resolution.

We now discuss the fees charged by Canadian acquirers. These acquirers typically charge merchants monthly. The charges consist of fixed and transaction-based fees. The latter are called merchant service charges (MSCs). This price structure, a two-part tariff, is common for service industries (Tirole 1988). The MSC structure charged in Canada differs between credit and debit cards. For most credit card payments, all three components are a percentage of the transaction amount. For most debit card transactions authorized by Chip and Personal Identification Number, the MSC is a fixed-fee per transaction, and the MIF is equal to zero (Note,

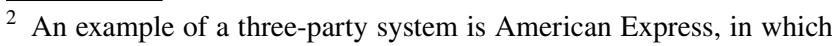
the network acquires merchants and issues payment cards.
} 
Table 1 Breakdown of acquirer charges borne by small and medium-sized businesses

\begin{tabular}{|c|c|c|c|c|c|c|c|c|}
\hline \multirow[t]{2}{*}{ Merchant revenue } & \multicolumn{4}{|c|}{ Monthly acquirer charges } & \multicolumn{3}{|c|}{ Percent of card sales } & \multirow[t]{2}{*}{ Cash only } \\
\hline & Fixed charges & MSC & Total charge & $\begin{array}{l}\text { Fixed charges } \\
\text { exceed MSC }\end{array}$ & Fixed charges & MSC & Total charge & \\
\hline$<250 \mathrm{~K}$ & $\$ 47$ & $\$ 84$ & $\$ 131$ & 0.47 & 2.04 & 1.78 & 3.82 & 0.41 \\
\hline $250 \mathrm{~K}-850 \mathrm{~K}$ & $\$ 57$ & $\$ 322$ & $\$ 379$ & 0.17 & 0.28 & 1.22 & 1.51 & 0.04 \\
\hline$>850 \mathrm{~K}$ & $\$ 68$ & $\$ 1,526$ & $\$ 1594$ & 0.06 & 0.06 & 1.20 & 1.26 & 0.04 \\
\hline All & $\$ 56$ & $\$ 483$ & $\$ 539$ & 0.26 & 0.50 & 1.34 & 1.84 & 0.24 \\
\hline
\end{tabular}

Rows represent business categories by total sales in cash and cards. The first three columns report acquirer charges in dollars. The fourth column reports the share of merchants that bear fixed charges higher than MSCs. The next three columns report charges as a percentage of processed card sales. The last column reports the share of businesses that accept cash only and do not accept debit or credit cards. The boundaries for small, medium and large businesses line up with revenue quartiles published by Innovation, Science and Development Canada (https://www.ic. gc.ca/app/scr/app/cis/performance/rev/44-45) for SMBs in the retail, restaurant and service industries

The table is based on 801 respondents; however, sample sizes vary in each cell. Estimates are computed after dropping the highest 5 percent of entries from the respective subsamples and taking the weighted sample mean. We drop the highest 5 percent since these businesses had low card volumes in the reporting period, resulting in higher proportional charges. Qualitatively, including all businesses does not change the relative size of the estimates when comparing across revenue categories. Untrimmed results are available upon request. The data were weighted to a nationally representative sample, using the survey weights constructed by (Chen and Shen 2017)

however, that contactless Interac Flash transactions, which are growing quickly, have an interchange fee, and that MasterCard contactless card payments below a certain threshold had a fixed-fee MIF instead of a percentage). Before 2015, the average MIF for a consumer credit card was 1.7 percent, (Hayashi et al. 2014). MasterCard set its NAF at 0.077 percent and Visa at 0.08 percent for processing Canadian ("domestic") credit cards. In sum, the merchant's cost is the total of fixed charges and the MSC, while the acquirer's revenue (net of MIF and NAF) is the total of fixed charges, and the AM shows how the MSC is distributed across the participants in the card payment system. The MSC usually has three components:

- the multilateral interchange fee (MIF) paid to the card issuer;

- the card network access fee (NAF), also called Acquiring Assessment fee (Visa), Acquiring Network Assessment Fee (MasterCard) or Switch Fee (Interac), which the acquirer must remit to the network;

- the acquirer-merchant fee (AM), which is the MSC net of NAF and MIF.

The 2015 RSCPM data are from a representative sample of small and medium-sized brick-and-mortar merchants that accepted payments at a physical POS in 2014. A detailed questionnaire on accepted payment methods and the associated costs was distributed to the respondents, along with a request to submit one of their merchant statements. The submitted merchant statements confirmed the two-part tariff and the components of the MSC, described above.

The data show that economies of scale exist for these merchants. With the two-part tariff structure consisting of a fixed monthly charge and per transaction MSC, merchants with higher total sales per month have a lower acquiring cost per dollar.

Table 1 breaks down acquirer charges by sales. All amounts are in Canadian dollars. We find that total acquirer charges in 2014 were around $\$ 539$ per month on average, representing 1.8 percent of the processed card sales. Of those charges, on average, fixed charges account for \$56 a month, or just under 0.5 percent of the total processed card sales. MSCs account for $\$ 483$ or 1.3 percent of the total processed card sales. SMBs with less than $\$ 250,000$ in annual sales are considered small, those with sales between $\$ 250,000$ and $\$ 850,000$ are considered medium, and those with sales above \$850,000 are considered large. Small businesses have the highest relative cost $(3.8$ percent of processed card sales), while large businesses have the lowest relative cost (1.3 percent). This difference is explained mainly by the share of fixed charges. For a typical small business, fixed charges make up about one-third of their monthly charges (\$47 out of a total of $\$ 131$ ), while they are just 4 percent for a larger SMB (\$68 out of a total of $\$ 1,594)$. Almost half of businesses with annual sales below $\$ 250,000$ report higher fixed charges than variable fees (MSCs) in a typical month. In contrast, only 17 percent of mid-range SMBs and 6 percent of the larger SMBs report this.

The relative impact of fixed charges could explain why 41 percent of the small brick-and-mortar businesses in our sample accept only cash. In our sample, the variable fees (MSCs), as a share of card sales, are also higher for the smaller SMBs, at 1.8 percent, compared with 1.2 percent for the larger SMBs. We do not break down the MSC further into its three components. However, Cohen (2010) states that the AM varies with merchants' turnover. Further, 
interchange fees (MIFs set by the network) vary across merchant categories, with the card type used by the cardholder and with the technology used for processing transactions. MIFs also vary with merchant sales. In 2014, lower MIFs were available to some Canadian merchants with at least $\$ 400$ million in sales (MasterCard) or least $\$ 850$ million in sales (Visa). The merchants in our sample are below this threshold. On one hand, the effect of these variations appears to be that the combined MSCs for debit and credit cards are higher for smaller merchants in the data. On the other hand, a different mix of debit and credit card transactions or lower average sales amounts at smaller businesses could also explain the difference in relative MSCs.

\section{Market structure}

This section describes market shares in the Canadian acquiring market. The market shares are computed from industry data and from the 2015 RSCPM (See Kosse et al. 2017 for a detailed description of the study design). While industry data paint a broad picture over time, the RSCPM data shed light on how the overall market shares might be driven by, for example, merchants' locations or their other banking choices.

Before describing the acquiring market structure, we provide some context for this market in Canada. While acquirers in Canada need not be Canadian banks, most acquirers have ties to Canadian banks or other deposit-taking institutions, and those links can influence merchants' choice of acquirer.

Until 2008, competition authorities required a non-duality framework, meaning one financial institution could not be a member of both Visa and MasterCard associations (Competition Bureau Canada 2008a, b). The purpose was to prevent a single financial institution from dominating the issuing or acquiring markets. Financial institutions generally issued and acquired for the credit card network they were a member of.

When the non-duality rule was dropped in 2008 , some Canadian banks had already transferred their acquiring operations to other, non-bank, entities. In 2000, the Royal Bank of Canada (RBC) and the Bank of Montreal (BMO), under joint investment, created Moneris Solutions, while the Canadian Imperial Bank of Commerce (CIBC) sold its acquiring operations and bought part of the acquirer Global Payments. In 2002, Scotiabank sold its acquiring business to Chase Paymentech Solutions. ${ }^{3}$

\footnotetext{
$\overline{3}$ As of 2019, CIBC and Scotiabank refer their business customers to Global Payments and Chase Paymentech Solutions, respectively. See CIBC (https://www.cibc.com/en/business/merchant-services.html) and Scotiabank (https://www.scotiabank.com/ca/en/small-business/ business-banking/partnership-hub/chase-merchant-services.html).
}

When the RSCPM sample was collected in 2015, Toronto Dominion Canada Trust (TD) and Desjardins Group still ran their own acquiring businesses. In November 2019, Global Payments bought Desjardins Group's Canadian acquiring business. As part of this transfer, Desjardins agreed to refer its clients exclusively to Global Payments for a period of 10 years (Financial Post 2019).

Figure 2 shows that from 2010 to 2018 five companies provided most acquiring services in Canada, measured by the number of transactions. Based on these estimates, from 2010 to 2018 Moneris Solutions was the largest acquirer in Canada, with a market share around 30 to 40 percent. Global Payments and Chase Paymentech Solutions followed, with around 20 percent of the market each, and TD Merchant Solutions had 10 to 15 percent. Desjardins was the fifthlargest acquirer with a market share just under 10 percent. These top five acquirers covered about 85 to 90 percent of card transactions in Canada and maintained stable market shares over this period.

Figure 3 shows the estimated market shares of acquirers in 2014 for SMBs, according to three different measures taken from the RSCPM data: number of merchants (SMBs), number of transactions, and transaction value. In these data, the top five acquirers also account for 85 to 90 percent of the transactions, but the share of Desjardins and smaller acquirers outside the top five is larger than in The Nilson Report's data discussed above. Other, smaller acquirers in these data include Elavon and First Data.

Several factors could explain the differences between the two sources. First, the RSCPM sample covers SMBs with a physical POS that operate in three industries: retail, food and accommodation services, and personal services. If an acquirer focuses on other industries, large businesses and chains, or online merchants, the RSCPM will underestimate its share. Finally, the accuracy of the market shares in Fig. 2 is limited because we have to estimate the volumes processed for Canada (see the note for Fig. 2).

The recent transfer of Desjardins' acquiring portfolio to Global Payments further enhances the role of the remaining four largest acquirers. The joint market share of these four firms provides a straightforward measure of concentration. This share has been above two-thirds since 2010, suggesting that the acquiring market is concentrated and stable by Canadian standards (Competition Bureau Canada 2011). A different concentration measure, the Herfindahl-Hirschman Index (HHI), also indicates that the market is concentrated. The HHI was used by the European Commission (2006) to study the structure of the acquiring market in various European Union member states. As illustrated in Fig. 2, the Canadian HHI has been above 2000 points since 2010, which is consistent with moderate concentration. 


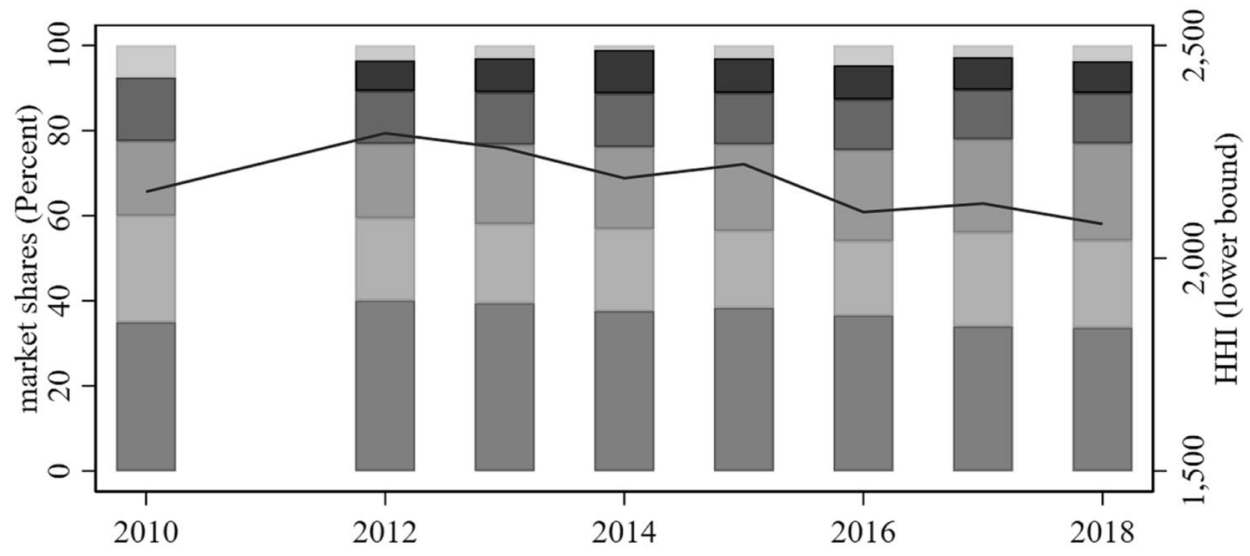

\begin{tabular}{|ll|}
\hline $\begin{array}{l}\text { Moneris Solutions } \\
\text { (left axis) }\end{array}$ & $\begin{array}{l}\text { Global Payments } \\
\text { (left axis) }\end{array}$ \\
$\begin{array}{l}\text { Chase Paymentech Solutions } \\
\text { (left axis) }\end{array}$ & $\begin{array}{l}\text { TD Merchant Solutions } \\
\text { (left axis) }\end{array}$ \\
$\begin{array}{l}\text { Desjardins Monetico } \\
\text { (left axis) }\end{array}$ & $\begin{array}{l}\text { Other acquirers } \\
\text { (left axis) }\end{array}$ \\
\hline HHI (right axis) & \\
\hline
\end{tabular}

Fig. 2 Canadian acquirers' market shares, 2010 to 2018. Note This chart was generated from multiple data sources: for 2010, it draws on a report by Deloitte (2010); for subsequent years, it draws on The Nilson Report as well as data reported by the Canadian Bankers Association and Interac. No data were available for 2011. The following assumptions were made to compute the market shares: The total volume of Visa and MasterCard transactions is from credit card statistics compiled by the Canadian Bankers Association. Data for Amex transactions are from The Nilson Report, and debit-transaction volumes are reported by the Interac association. Moneris, Global Pay- ments and TD Canada volumes are global volume minus US volume, Europe volume and Asia-Pacific volume. Chase Paymentech Solutions volume is assumed to grow at the same rate as Chase US, because no separate numbers are available. Desjardins is taken as reported by The Nilson Report. To compute the share, estimated processed volume for each acquirer (from The Nilson Report) is divided by the estimated total volume of card transactions (Canadian Bankers Association, Interac and Amex). The Herfindahl-Hirschman Index (HHI) is computed as the sum of squared market shares (in percent). The highest possible HHI is 10,000 and corresponds to a monopoly
Fig. 3 Acquirers' market shares in 2014 (RSCPM). Source 2015 RSCPM data. The data were weighted to a nationally representative sample, using the survey weights constructed by Chen and Shen (2017)

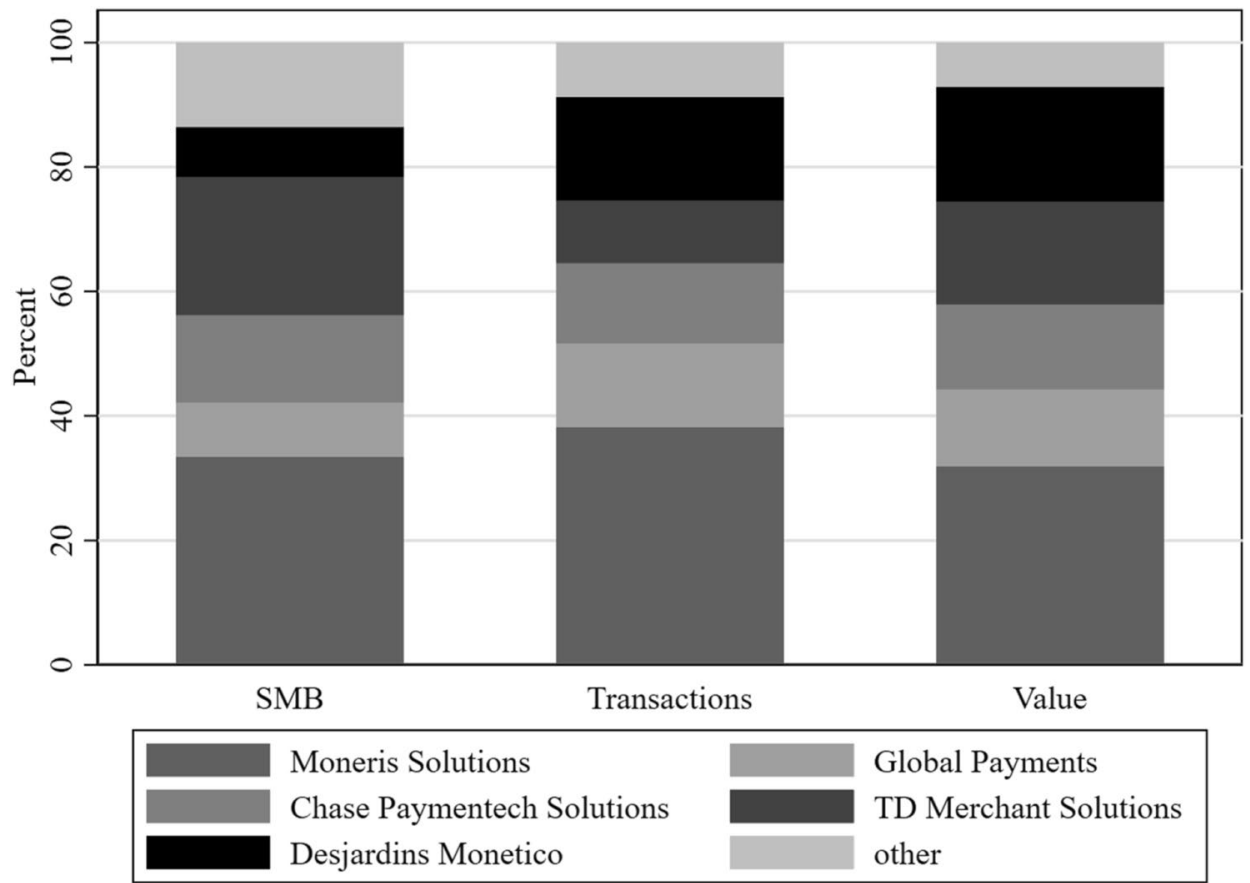


Fig. 4 Concentration in the acquiring market and cash preference. Note This chart plots the share of cash-only businesses against the HerfindahlHirschman Index (HHI) for five regions of Canada: Ontario $(\mathrm{ON})$, British Columbia (BC), Atlantic provinces (AT), Quebec $(\mathrm{QC})$ and Prairie provinces (PR). The orange line shows how much of the increase in the cash share is correlated with the increase in the HHI. Source: 2015 RSCPM data. The data were weighted to a nationally representative sample, using the survey weights constructed by Chen and Shen (2017)

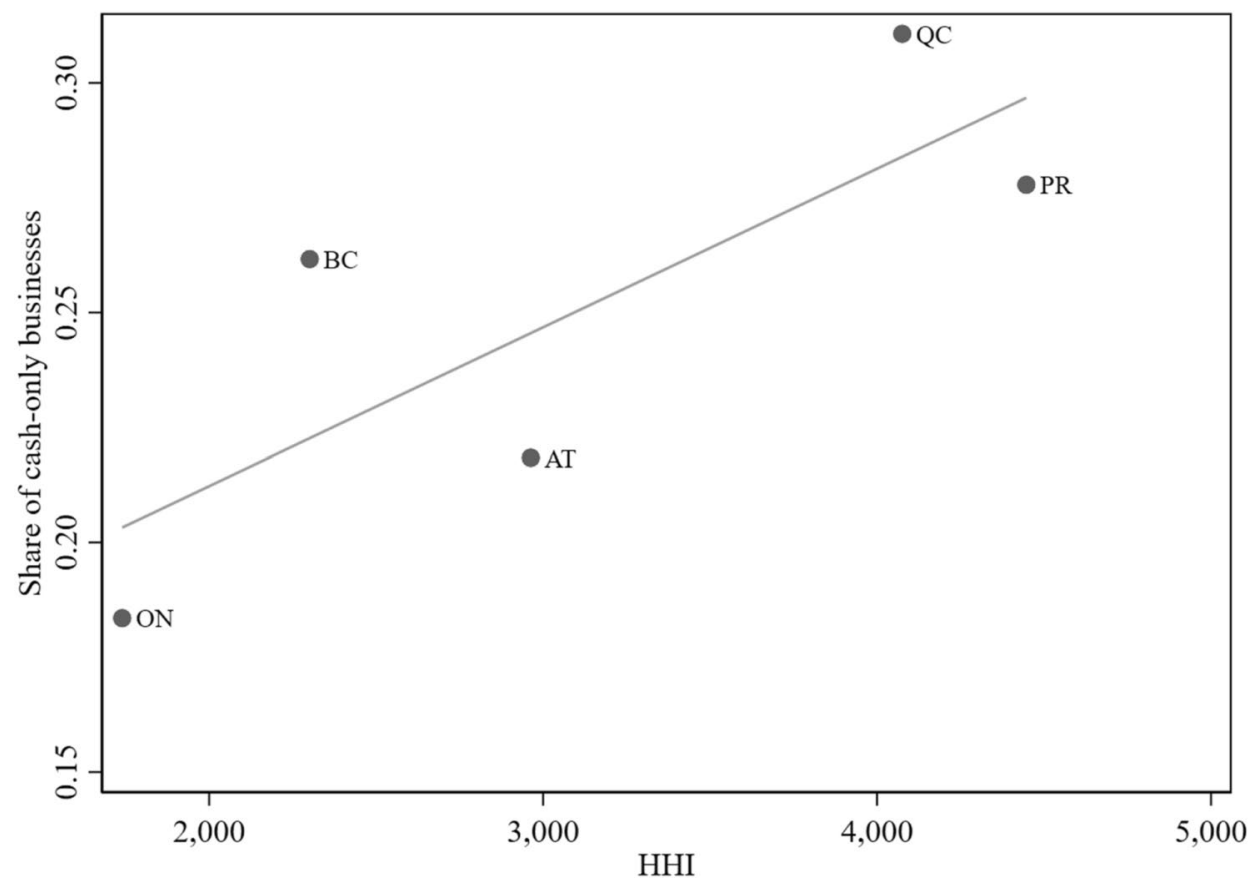

The RSCPM and other surveys have found that cash and card use vary across regions in Canada. For example, businesses and consumers rely more on cash in Quebec than in other regions (Henry et al. 2018). We also find regional variation in market concentration. The acquiring market appears to be most concentrated in the Prairies and Quebec and least concentrated in Ontario (Fig. 4).

\section{Potential drivers of market structure}

A concentrated market has often been associated with high fixed set-up and operating costs (Tirole 1988), or with brand loyalty (consumer "stickiness") or regulation (Bain 1959). These features, in turn, could generate barriers to entry that lead to a concentrated market structure. In this section, we explain how the costs of doing business and brand loyalty appear to be relevant factors for the acquiring market in Canada.

Acquirers incur ongoing fixed costs and variable costs (Cohen 2010). Fixed operating costs are incurred regardless of how many merchants are acquired; that is, these costs prevail whether the acquirer signs up 10 or 10,000 merchants. Variable costs, however, vary directly with the number of merchants acquired and with the number and value of transactions processed.

Acquirers can bear large fixed costs for setting up, running, and modernizing their payment infrastructure. TPAs may avoid some of these costs by using the infrastructure of another acquirer. Furthermore, there are costs for every signed-up merchant. These include customer service and recruitment, preparation and provision of statements, and maintenance and technical support for POS terminals. These costs appear as fixed charges to the merchant (as statement fees or equipment rental costs), but they are variable for the acquirer according to the number of merchants served. Variable costs for the acquirers also include the fees they pay to the card issuers (MIF) and card networks (NAF). The acquirer does not set these fees and must remit them to card issuers and networks (Moneris 2020).

Other variable costs come from disputed card transactions and "float fees" related to MIF and AM. These pose financial risks for acquirers that increase with the transaction volume and amount.

According to guidelines published by MasterCard and Visa, the acquirer might have to cover a disputed, previously authorized transaction when the merchant is found liable but does not have the funds to cover the loss (MasterCard 2016; Visa 2018).

Financial risks due to float fees are incurred because the acquirer deposits funds into the merchant's account shortly after a purchase but receives the MSC only later, typically after the monthly statement has been issued. Another risk related to timing lags can occur when the cardholder uses their credit card for a reservation or booking, and the acquirer sends the funds to the merchant before the cardholder makes the payment.

Merchant charges in a concentrated and stable acquiring market are not necessarily higher than they would be in a more fragmented market. Similar to Allen and Engert's (2007) work on concentration and efficiency in the Canadian 
Fig. 5 US acquirers' market shares 2012 to 2019. Note

Source is The Nilson Report 1059, 1074, 1082, 1097, 1105, $1119,1127,1141,1149,1163$, 1171, 1169. Market shares are computed by dividing the transaction count reported by Nilson for each acquirer by the total number of transactions on US issued cards (excluding prepaid cards and American Express credit cards). The alternative HHI was computed by grouping the market shares of acquirers that have merged or formed partnerships or alliances

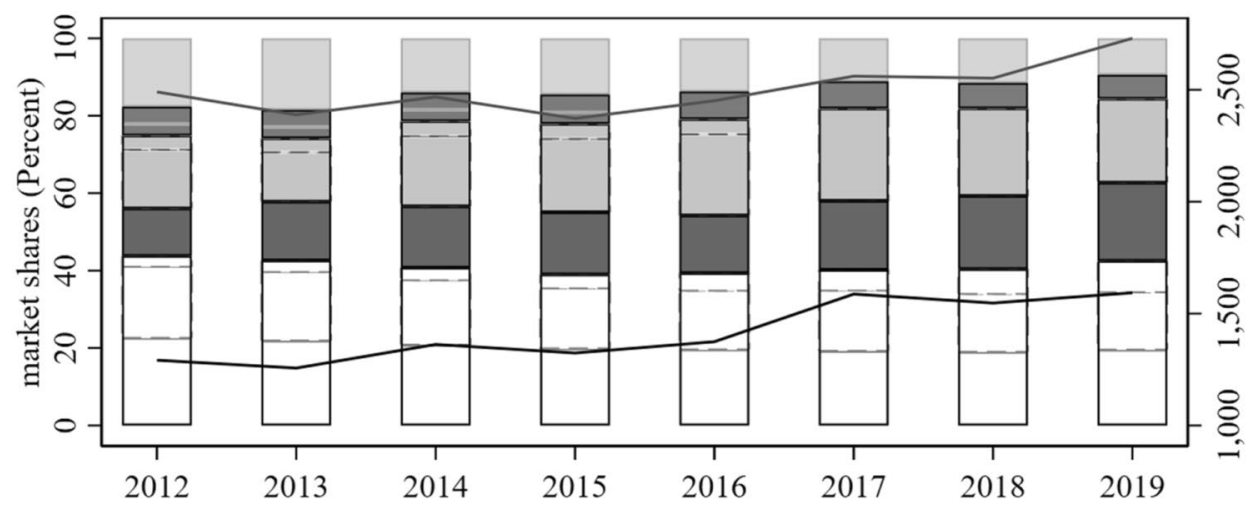

\begin{tabular}{|c|c|}
\hline & First Data, Bank of America, Wells Fargo (left axis) \\
\hline & Chase Paymentech (left axis) \\
\hline & Vantiv, WorldPay, FIS (from 2017) (left axis) \\
\hline & Global Payments, Heartland (until 2016) (left axis) \\
\hline & Other acquirers (left axis) \\
\hline & HHI (right axis) \\
\hline & alternative HHI (right axis) \\
\hline
\end{tabular}

banking sector, we see three main reasons why merchant charges would not decrease in a less concentrated market.

First, in the presence of high fixed costs, the market would also face trade-offs between concentration and efficiency. While a less concentrated market with many small acquirers could be more competitive, prices charged to merchants would not necessarily be lower because each small acquirer would have a large fixed cost to distribute among fewer subscribing merchants. Second, stability in the acquiring market also means that existing acquirers are reliable. Merchants usually want to be sure that transactions settle without problems or frictions and that they can access their funds as soon as possible after supplying the good or service to the cardholder. Third, even in a concentrated market, large acquirers might not be able to charge excessive prices or provide poor service if there is a credible threat from existing competitors, or from potential entrants ("contestability"), where a new firm would take up the dissatisfied consumers.

In summary, since participating in the acquiring market requires a large investment, to operate profitably an acquirer must attract and retain many merchants and large transaction volumes. High fixed costs, therefore, could be part of the explanation for why the acquiring market in Canada and elsewhere is concentrated and stable.

\subsection{The Canadian context}

Indeed, the structure of the Canadian acquiring market is similar to that of acquiring markets in other countries with mature card payment systems. Based on data from The
Nilson Report, the five largest acquirers in the US market accounted for about 80 percent of the transactions processed in 2018 and that their share has been increasing (see Fig. 5). Likewise, four acquirers have dominated the Australian market (Katz 2001; The Nilson Report).

Evans and Schmalensee (2005) conclude that the US acquiring market is concentrated and yet competitive. First, they argue that the AM portion of the MSC is generally much smaller than the MIF portion and has been falling over time. For Canadian merchants, the AM is also much lower than the MIF, but our data show that conclusions about acquirer pricing need to consider both AM and fixed charges. Thus, it is unclear how and whether Evans and Schmalensee's reasoning can be applied to the Canadian market.

The second part of their argument is that merchants can obtain quotes from several acquirers and switch quite easily. The cost of switching in the Canadian acquiring market is an open question. To address it, we would need to understand how often and under what circumstances Canadian merchants switch acquirers. The Financial Consumer Agency of Canada's (2015) Code of Conduct for the Credit and Debit Card Industry in Canada specifies that merchants' fixed-term contracts with acquirers can be extended only for a period of six months after the initial fixed term, thus giving merchants the option to switch after the initial contract expires. However, this rule came into effect only in 2016, after the 2015 RSCPM was conducted.

The involvement of third parties in the relationship between merchant and acquirer should also be discussed. 
Fig. 6 Acquirers' market shares in RSCPM conditioned on merchant's main bank. Note The chart shows market shares of acquirers among the clients of a particular financial institution. Market shares are measured by the fraction of processed transactions. Bars marked with $\mathrm{X}$ indicated the acquirer associated with the financial institution. Source: 2015 RSCPM data. The data were weighted to a nationally representative sample, using the survey weights constructed by (Chen and Shen 2017)

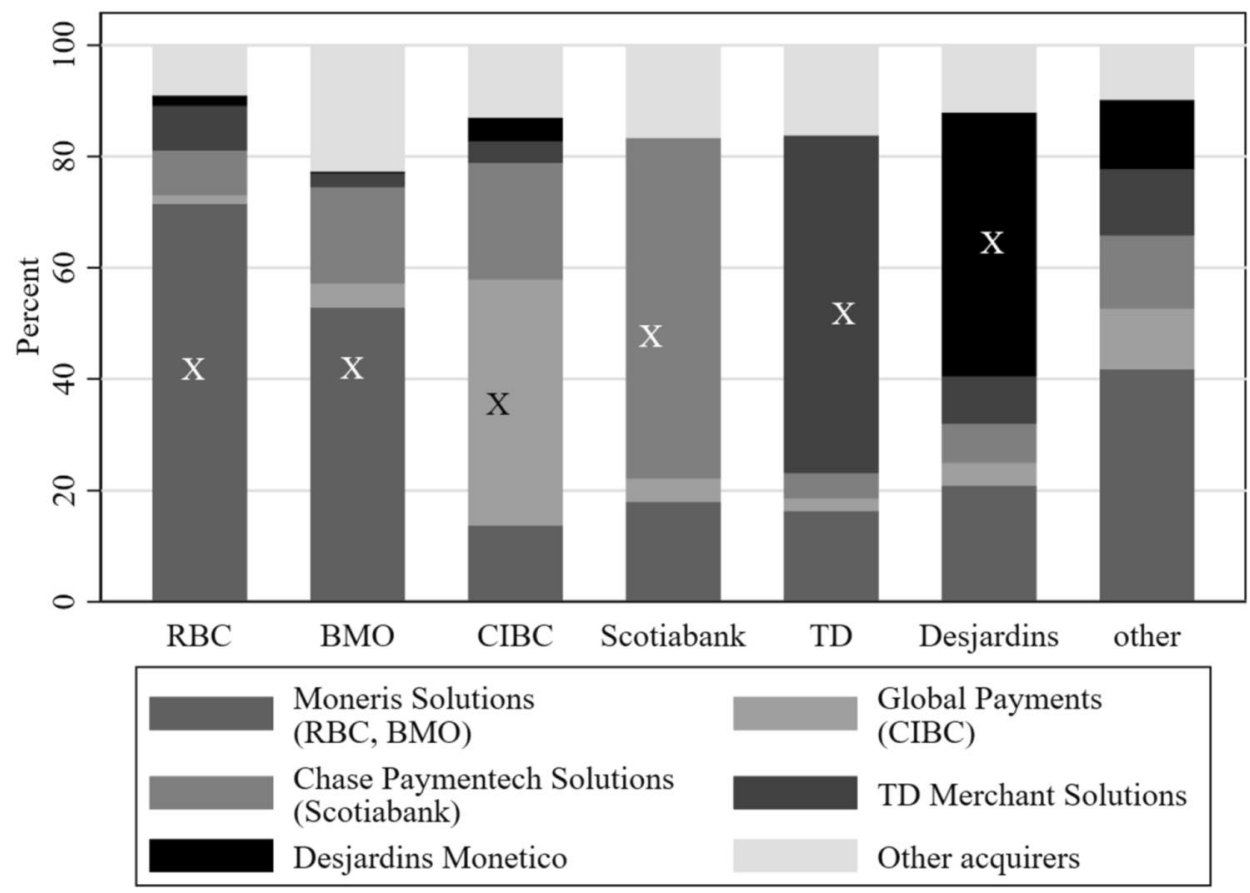

These parties could be banks, merchant organizations, or TPAs.

We find that at least half the merchants in our dataset appear to bundle acquiring services with their main bank account, which could make switching more difficult. Figure 6 shows the percentage of merchants in our study whose acquirer is related to their main bank. We see that each financial institution's affiliated acquirer is the dominant acquirer for each financial institution's customers. Put differently, the share of the affiliated acquirer is larger in each column than it is overall, and these differences are statistically significant. ${ }^{4}$ For example, around 55 percent of combined RBC and BMO customers use Moneris as their acquirer, while only 20 percent of the clients of other banks use Moneris. This means that a business banking with $\mathrm{RBC}$ or $\mathrm{BMO}$ is more than twice as likely to use Moneris as its acquirer than are businesses that bank with other financial institutions.

While large merchants could sponsor a new, lower-cost entrant, typically they negotiate favorable rates with their existing acquirer (De Armas 2010). Smaller merchants, however, may have limited bargaining power. One way for an acquirer to attract small merchants and for smaller merchants to obtain more favorable pricing would be exclusive member pricing for small business and industry associations. Examples include the partnerships between Chase Paymentech and the Canadian Federation of Independent Business (2020) and between Elavon and Costco Wholesale (2020).

\footnotetext{
4 This is based on a Chi-squared test, available upon request.
}

Square is a relatively new entrant in the Canadian payment processing market. It offers services without monthly fixed charges; that is, the merchant pays only the (variable) MSC. Square uses the infrastructure of other acquirers to route its transactions. As currently advertised on the Square website, its fees are 2.65 percent of PIN credit card transactions and 10 cents per Interac debit card transaction.

\subsection{The United States context}

In the US acquiring market, in contrast to Canada, TPAs play a more prominent role, in particular for small and mediumsized merchants (FDIC 2007). We explain why this matters in interpreting the concentration measures in Fig. 5 and in understanding the prices faced by merchants. DeGennaro (2006) explains that some of the largest participants in the US market are TPAs that use other acquirers for access to the card network. As an example, in the year 2012, while merchants who used Bank of America accounted for the second- most largest volume of transactions, their transactions were actually routed through infrastructure belonging to First Data (the largest in terms of transactions directly received from merchants). If market shares of groups of firms according to partnerships, alliances, acquisitions or mergers determine the concentration measure (as done in Fig. 5) then the four largest groups processed 80 to 90 percent of the transactions for the period from 2012 to 2019. Unsurprisingly, the HHI as a measure of market concentration is also higher when partnerships, alliances, acquisitions or mergers are grouped together, increasing by almost 1000 points (the alternative HHI in Fig. 5). However, more 
acquirers and payment processors operate in the US market than in the Canadian market. The Nilson Report lists 150 companies that merchants can contract with, although many of them are not full-service acquirers with direct access to the networks. For a merchant who purchases payment processing services from a TPA, the AM and monthly fixed-fee would cover the cost of both the TPA and of the acquirer that provides network access. While AM has been falling, according to Evans and Schmalensee (2005), their paper does not consider recent developments in the US acquiring market. Many of the observations for our sample of small and medium-sized Canadian merchants might carry over to similar US merchants: Kjos (2007) highlights the importance of monthly fixed fees for smaller merchants. Smaller US merchants also usually face higher MIFs than their larger counterparts.

We observe that the fees paid by US merchants could have a different structure than those in Canada. The Federal Deposit Insurance Corporation (2007) states that US merchants often pay blended MSC that do not separate the AM, MIF and NAF components, a key difference to the FCAC's requirement to provide such a breakdown to Canadian merchants. In contrast to the voluntary agreement about credit card interchange in Canada., US public authorities capped some debit card MIFs in 2012, but not credit card MIFs. As stated by The Nilson Report (1022, 1176) average US MSCs (debit and credit cards together) dropped from 1.7 percent to 1.5 percent between 2011 and 2012 and rose slightly to 1.54 percent by 2019. While MSCs for debit cards continued to decrease after 2012, this was offset by an increase for credit card MSCs. At the same time, Hayashi et al. (2020) shows that credit card MIFs for each merchant or card type have been quite stable since 2012. Although an increase in AM could explain the overall higher MSCs for credit cards, a shift of credit card payments to smaller or riskier merchants, online payments or premium cards would also explain it.

While the relationship between Canadian acquirers and merchants fall under the FCAC's Code of Conduct, the regulation and oversight of an US acquirer may fall to overlapping financial institution authorities. If the acquirer belongs to or is sponsored by a deposit-taking financial institution, the Federal Deposit Insurance Corporation (FDIC 2007) regulates the latter and their relationship with merchants and TPAs, in the majority of cases. In these situations, the Office of the Comptroller of Currency (OCC 2014), the Federal Reserve, or state banking authorities might also examine the acquirer's operations to ensure safety and soundness. These authorities also monitor the risks that acquirers take on when underwriting merchants. Finally, the Federal Financial Institutions Examination Council (FFIC 2012) may examine any third-party, including acquirers and TPAs, that provides major services to a financial institution regulated by these bodies.

\subsection{Two-sided market considerations}

Acquirers, merchants, and TPAs represent one side of the card payment market. As this market is two-sided (Rochet and Tirole 2002; Fung et al. 2017), the economic interpretation of the acquirer-merchant market must also consider the issuer-cardholder side. On the one hand, as Fig. 4 shows, the share of cash-only businesses seems to increase with concentration. In this regard, the Prairies and Quebec have the highest concentration and the highest cash-only (lowest card acceptance) rates. Ontario has the lowest concentration, with the highest card acceptance rate. The acquiring market might be seen as less competitive in the Prairies and Quebec. This could lead to high acquiring fees that might discourage smaller merchants from accepting cards.

On the other hand, influences on the cardholder side of the market could also explain this pattern. Huynh et al. (2019) show empirically that merchant acceptance responds to consumer payment preferences, and Henry et al. (2018) find that consumers in Quebec have a greater relative preference for cash over cards. In this case, the demand for acquiring services could be lower in Quebec, and acquirers might choose not to invest as much, given local preferences. Also, note that British Columbia and the Prairies have similar levels of card acceptance, but the acquiring market in British Columbia is significantly less concentrated than in the Prairies. Clearly, more data from both the acquirer-merchant and issuer-consumer sides are needed to assess the statistical and economic relationship between concentration and cash preference.

\section{Concluding remarks}

This article describes the card acquiring market in Canada. We use the 2015 RSCPM and industry sources to shed light on market shares, prices, and costs. We find that five firms supplied the majority of acquiring services between 2010 and 2018. The market appears to be stable and mature, and new entrants would face challenges, including economies of scale and merchants' preference to bundle acquiring with other banking services. Furthermore, acquirers use two-part tariff pricing, and fixed acquirer charges might affect card acceptance for small merchants to the same extent as transaction-level charges. This work complements Fung et al.'s (2018) work on the latter type of charges. Finally, the data suggest that market structures and card acceptance differed across regions.

We point out several areas for future research. First, the analysis is based on survey data for 2014. After the period covered by the survey, the Code of Conduct for the Credit and Debit Card Industry in Canada was updated in 2015 and card networks voluntary committed to the Department 
of Finance (2018) to reduce interchange fees. Specifically, The Department of Finance (2018) announced that Visa and MasterCard would adjust their interchange fees with the aim of "leveling the playing field," effective in early 2014 and again in 2020. The exit of Desjardins from the acquiring market might also affect the market structure. We need more recent data to understand how and whether these developments also changed the market shares and pricing of acquirer services.

Second, this analysis of acquirer fees applies to small and medium-sized businesses. Each large business or chain would contribute a considerable number of transactions to the market share of their chosen acquirer. Based on our analysis, large firms probably pay less per dollar of processed card payments than the businesses in our sample. However, simple numerical extrapolations would likely not be accurate. Jiongo (2017) discusses this issue further. A related caveat is that smaller businesses have high fixed costs compared with their revenue for cost items other than payment processing. ${ }^{5}$ Also, although economic theory usually discusses two-part tariffs in relation to market power, many service industries use this type of pricing, and the relationship between pricing structure and competition is an active area of research (Lambrecht et al. 2012). Combining insights from this area with research on two-sided card payment systems would therefore be valuable.

Third, while some of our results might apply to other jurisdictions than Canada, payment industries often have unique features that can drive their market structures. For the US market specifically, we find some parallels to the Canadian market; however, important differences exist. One of them is the prominence of third-party agents that act as brokers between acquirers and merchants.

Further, and perhaps more relevant in terms of the economic interpretation, a concentrated and stable acquiring industry could function in an efficient and reliable manner. Card ecosystems around the world have seen the involvement of public authority (Hayashi and Maniff 2019). However, we caution that our analysis cannot assess the efficiency and degree of competition in the Canadian acquiring industry. We leave this assessment as an open research question.

Acknowledgments We thank Walter Engert, Ben Fung, Fumiko Hayashi, Kim P. Huynh, Sajjad Jafri, Charles Kahn, Dave Lott, and Alex Shcherbakov for helpful discussions, comments and suggestions. We thank Dave Lott of the Federal Reserve Bank of Atlanta for discussing the US context with us. Jozsef Molnar acknowledges the hospitality of the Bank of Canada for his one-year assignment when this paper was written.

\footnotetext{
${ }^{5}$ See, for example, the financial performance indicators published by Innovation, Science and Economic Development Canada (https:// www.ic.gc.ca/app/scr/app/cis/performance/rev/445).
}

\section{References}

Allen, Jason, and Walter Engert. 2007. Efficiency and Competition in Canadian Banking. Bank of Canada Review (Summer): 33-45.

Bain, Joe S.. 1959. Industrial Organization. New York: Wiley.

Chen, Heng, Walter Engert, Kim Huynh, Gradon Nicholls, Mitchell Nicholson, and Julia Zhu, 2020. Cash and COVID-19: The impact of the pandemic on demand for and use of cash. Bank of Canada Discussion Papers 2020-6.

Chen, Heng, and Rallye Shen. 2017. The Bank of Canada 2015 Retailer Survey on the Cost of Payment Methods: Calibration for SingleLocation Retailers. Bank of Canada Technical Report No.109.

Cohen, Jordan. 2010. Witness Statement of Jordan Cohen. Available at https://decisions.ct-tc.gc.ca/ct-tc/cdo/en/item/463342/index.do.

Canadian Federation of Independent Business. 2020. Chase Discounts and Savings for Small Business. Available at https://www.cfibfcei.ca/en/member-savings-benefits/chase

Competition Bureau Canada. 2008. The Competition Bureau's letter to financial institutions-Duality and dual Governance of credit card networks in Canada. https://www.competitionbureau.gc.ca/ eic/site/cb-bc.nsf/eng/02749.html.

Competition Bureau Canada. 2008. Merger Enforcement Guidelines. https://www.competitionbureau.gc.ca/eic/site/cb-bc.nsf/vwapj/ cb-meg-2011-e.pdf/\$FILE/cb-meg-2011-e.pdf.

Costco Wholesale.2020. Costco Payment Processing. Available at https://www.costcopaymentprocessing.ca/index.html

De Armas, Mario. 2010. Witness Statement of Mario De Armas. Available at https://decisions.ct-tc.gc.ca/ct-tc/cdo/en/item/463361/ index.do.

DeGennaro, Ramon P. 2006. Merchant Acquirers and Payment Card Processors: A Look Inside the Black Box. Federal Reserve Bank of Atlanta. Economic Review 91 (1): 27-42.

Deloitte. 2010. Canadian Payments Landscape. Prepared for the Task Force for the Payments System Review.

Department of Finance. 2018. Backgrounder: New Voluntary Commitments From Payment Card Networks. https://www.canada.ca/en/ department-finance/news/2018/08/backgrounder-new-voluntarycommitments-from-payment-card-networks.html

European Commission. 2006. Interim Report I: Payment Cards-Sector Inquiry under Article 17 Regulation 1/2003 on Retail Banking. Available at https://ec.europa.eu/competition/sectors/financial_ services/inquiries/interim_report_1.pdf.

Financial Consumer Agency of Canada. 2015. Code of Conduct for the Credit and Debit Card Industry in Canada. Available at https:// www.canada.ca/en/financial-consumer-agency/services/industry/ laws-regulations/credit-debit-code-conduct.html

Financial Post. 2019. Global Payments Announces Strategic Partnership with Desjardins Group in Canada. https://financialpost. com/pmn/press-releases-pmn/business-wire-news-releases-pmn/ global-payments-announces-strategic-partnership-with-desja rdins-group-in-canada.

Evans, David S., and Richard Schmalensee. 2005. Paying with Plastic: The Digital Revolution in Buying and Borrowing, 2nd ed. Cambridge: MIT Press.

Federal Deposit Insurance Corporation (FDIC). 2007. Credit Card Activities Manual https://www.fdic.gov/regulations/examinatio ns/credit_card/index.html

Federal Financial Institutions Examination Council. 2012. Supervision of Technology Service Providers, IT Examination Handbook. https://ithandbook.ffiec.gov/media/274876/ffiec_itbooklet_super visionoftechnologyserviceproviders.pdf

Fung, Ben, Kim P. Huynh, and Anneke Kosse. 2017. Acceptance and Use of Payments at the Point of Sale in Canada. Bank of Canada Review (Autumn): 14-26. 
Fung, Ben, P. Kim, Kerry Nield Huynh, and Angelika Welte. 2018. Merchant Acceptance of Cash and Credit Cards at the Point of Sale. Journal of Payments Strategy \& Systems 12 (2): 150-165.

Hayashi, Fumiko, Emily Cuddy, and Joshua Hanson. 2014. Credit and Debit Card Interchange Fees in Various Countries: August 2014 Update. Federal Reserve Bank of Kansas City: Payments System Research Department.

Hayashi, Fumiko, and Jessie L. Maniff. 2019. Public Authority Involvement in Payment Card Markets: Various Countries. August 2019 Update. Payments System Research Department, Federal Reserve Bank of Kansas City.

Hayashi, Fumiko, and Rebecca Ruiz. 2020. Credit and Debit Card Interchange Fees Assessed to Merchants in the United States. August 2020 Update. Payments System Research Department, Federal Reserve Bank of Kansas City.

Jiongo, Valéry D. 2017. The Bank of Canada 2015 Retailer Survey on the Cost of Payment Methods: Estimation of the Total Private Cost for Large Businesses. Bank of Canada Technical Report No. 110 .

Henry, Christopher S., Kim P. Huynh and Angelika Welte. 2018. 2017 Methods-of-Payment Survey Report. Bank of Canada Staff Discussion Paper No. 2018-17.

Ho, Chun-Yo, Li Xu, and Daiqiang Zhang. 2020. Price Negotiation with Merchant Heterogeneity in the Payment Card Industry. The Review of Economics and Statistics (forthcoming; posted October 30)

Huynh, Kim P., Gradon Nicholls, and Oleksandr Shcherbakov. 2019. Explaining the Interplay Between Merchant Acceptance and Consumer Adoption in Two-Sided Markets for Payment Methods. Bank of Canada Staff Working Paper No. 2019-32.

Huynh, Kim, Helen Lao, Patrick Sabourin, and Angelika Welte, 2020. What do High-Frequency Expenditure Network Data Reveal About Spending and Inflation During COVID-19? Bank of Canada, Staff Analytical Notes 2020-20.

Katz, Michael L. 2001. Reform of Credit Card Schemes in Australia II. Report commissioned by the Reserve Bank of Australia.

Kjos, Ann. 2007. The Merchant-Acquiring Side of the Payment Card Industry: Structure, Operations, and Challenges. Payment Cards Center Discussion Paper. Philadelphia: Federal Reserve Bank of Philadelphia.

Kosse, Anneke, Heng Chen, Marie-Hélène Felt, Valéry D. Jiongo, Kerry Nield, and Angelika Welte. 2017. The Costs of Point-ofSale Payments in Canada. Bank of Canada Staff Discussion Paper No. 2017-4.

Lambrecht, Anja, Katja Seim, Naufel Vilcassim, Amar Cheema, Yuxin Chen, Gregory S.. Crawford, Kartik Hosanagar, Raghuram Iyengar, Oded Koenigsberg, Robin Lee, Eugenio J.. Miravete, and Ozge Sahin. 2012. Price Discrimination in Service Industries. Marketing Letters 23 (2): 423-438.

MasterCard. 2020. MasterCard Rules. https://www.MasterCard.us/ en-us/business/overview/support/rules.html (Accessed September 28, 2020).

MasterCard. 2016. Chargeback Guide. https://www.MasterCard.ca/ content/dam/mccom/en-ca/Documents/Chargeback\%20Guide.pdf

Moneris. 2020. Interchange 101: What It Is and How It's Determined. https://insights.moneris.com/business-matters/interchange-101what-it-is-and-how-its-determined

Office of the Comptroller of the Currency (OCC). 2014. Merchant Processing: Revised Comptroller's Handbook Booklet. https:// www.occ.treas.gov/publications-and-resources/publications/ comptrollers-handbook/files/merchant-processing/pub-ch-merch ant-processing.pdf

Square. 2017. Payment Terms, https://squareup.com/ca/en/legal/gener $\mathrm{al} /$ payment

The Nilson Report. 2013-2019. Issues 1013,1029,1036, 1049, 1059, 1065, 1071, 1073, 1074, 1082, 1087, 1094, 1095, 1097,
$1105,1110,1116,1117,1119,1127,1132,1139,1141,1149,1153$, $1159,1161,1163,1169$ and 1171

Rochet, Jean-Charles., and Jean Tirole. 2002. Cooperation among Competitors: Some Economics of Payment Card Associations. RAND Journal of Economics 33 (4): 549-570.

Tirole, Jean. 1988. The Theory of Industrial Organization. Cambridge: MIT Press.

Tirole, Jean. 2011. Payment Card Regulation and the Use of Economic Analysis in Antitrust. Competition Policy International 7 (1): 136-158.

Van Duynhoven, Jeff. 2010. Witness Statement of Jeff Van Duynhoven. https://decisions.ct-tc.gc.ca/ct-tc/cdo/en/item/463437/index.do (Accessed April 29, 2020).

Visa. 2018. Dispute Management Guidelines for Visa Merchants. https://www.visa.ca/dam/VCOM/download/merchants/charg eback-management-guidelines-for-visa-merchants.pdf

Visa. 2020. Info for Service Providers. https://www.visa.ca/en_CA/ partner-with-us/info-for-partners/info-for-service-providers.html (Accessed September 28, 2020).

Publisher's Note Springer Nature remains neutral with regard to jurisdictional claims in published maps and institutional affiliations.

Angelika Welte is a Senior Economist in the Currency Economic Research and Analysis Department at the Bank of Canada. She is an expert on the demand for cash, card payment systems and transaction data. Dr. Welte has worked on several high-impact research projects to support evidence-based policy analysis and decision making. Her research spans modelling consumer payment choice, adoption of financial innovations, and the effects of payment pricing on consumer and merchant groups. Her recent research studies the linkage between household spending and payment systems data. She also has a key role in developing and implementing surveys of consumer and merchants on the subject of payments. Dr. Welte holds a Master's degree in Economic from Carleton University and $\mathrm{PhD}$ in Mathematics from the University of Ottawa. Before joining the Bank of Canada, she was a postdoctoral fellow and instructor.

Jozsef Molnar is an expert in the fields of industrial organization, econometrics, and competition law. The paper was written while he spent a one-year assignment at the Bank of Canada. Previously, as a member of the European Commission's Directorate-General for Competition's Chief Economist Team, he provided economic and econometric expert advice and analysis and participated in the decision-making on antitrust and competition issues at the highest level. He worked on numerous high-profile mergers (including airlines, retail, basic materials, energy, and telecommunication sectors), antitrust (airline codeshares and alliances), and ex-post impact assessment projects. Dr. Molnar also worked as an Economic Adviser for the United Kingdom's Competition Commission, a visiting researcher at the Einaudi Institute for Finance and Economics (research institute of the Banca d'Italia), at the National Bank of Hungary, and at the Bank of Finland. As an academic, Dr. Molnar was a Marie Curie postdoctoral fellow in the European Commission's Research Training Network and an ESRC Research Fellow at the London Business School. He taught different subjects to students at various levels (undergraduate, Ph.D., and MBA) in different countries (at Budapest University of Economics, at Northwestern University, at Mendoza College of Business, University of Notre Dame, and at Central European University Business School). His research focused on auction theory, empirical industrial organization, and banking. Dr. Molnar received his Ph.D. in Economics from Northwestern University in 2001. 